\title{
Retraction
}

\section{Retracted: The Split Common Fixed Point Problem for Quasi-Total Asymptotically Nonexpansive Uniformly Lipschitzian Mappings}

\begin{abstract}
Applied Analysis
Received 15 October 2012; Accepted 15 October 2012

Copyright (C) 2012 Abstract and Applied Analysis. This is an open access article distributed under the Creative Commons Attribution License, which permits unrestricted use, distribution, and reproduction in any medium, provided the original work is properly cited.
\end{abstract}

This article has been retracted as it is found to contain a substantial amount of material, without referencing, from the paper "The Split Common Fixed Point Problem for Total Asymptotically Strictly Pseudocontractive Mappings," Shihsen Chang, Lin Wang, Yong Kun Tang and Li Yang, Journal of Applied Mathematics, vol. 2012, Article ID 385638, 13 pages, 2012. doi:10.1155/2012/385638 [1].

\section{References}

[1] J. Na, L. Wang, and Z. Ma, "The split common fixed point problem for quasi-total asymptotically nonexpansive uniformly Lipschitzian mappings," Abstract and Applied Analysis, vol. 2012, Article ID 768591, 9 pages, 2012. 


\title{
Research Article
}

\section{The Split Common Fixed Point Problem for Quasi-Total Asymptotically Nonexpansive Uniformly Lipschitzian Mappings}

\author{
Jing $\mathrm{Na}^{1}{ }^{1}$ Lin Wang, ${ }^{1}$ and Zhaoli $\mathrm{Ma}^{2}$ \\ ${ }^{1}$ College of Statistics and Mathematics, Yunnan University of Finance and Economics, Yunnan, \\ Kunming 650221, China \\ 2 School of Information Engineering, The College of Arts and Sciences, Yunnan Normal University, \\ Yunnan, Kunming 650222, China
}

Correspondence should be addressed to Lin Wang,w164mail@yahoo.com.cn

Received 9 February 2012; Accepted 12 March 2012

Academic Editor: Paul Eloe

Copyright (C) 2012 Jing Na et al. This is an open access article distributed under the Creative Commons Attribution License, which permits unrestricted use, distribution, and reproduction in any medium, provided the original work is properly cited.

We introduce an algorithm for solving the split common fixed point problem for quasi-total asymptotically nonexpansive uniformly Lipschitzian mapping in Hilbert spaces. The results presented in this paper improve and extend some recent corresponding results.

\section{Introduction and Preliminaries}

Let $H_{1}$ and $H_{2}$ be real Hilbert spaces with inner product $\langle\cdot, \cdot\rangle$ and norm $\|\cdot\|$. Let $C$ and $Q$ be nonempty closed convex subsets of $H_{1}$ and $H_{2}$, respectively. The split feasibility problem (SFP) is formulated as finding a point $x^{*}$ with the property

$$
x^{*} \in C, \quad A x^{*} \in Q,
$$

where $A: H_{1} \rightarrow H_{2}$ is a bounded linear operator.

The SFP in finite-dimensional Hilbert spaces was first introduced by Censor and Elfving [1] for modeling inverse problems which arise from phase retrievals and in medical image reconstruction [2]. Recently, it has been found that the SFP can also be used in various disciplines such as image restoration, computer tomograph, and radiation therapy treatment planning [1, 3-7]. The SFP in infinite-dimensional Hilbert spaces can be found in [8-16]. 
The split common fixed point problem (SCFP) is a generalization of the split feasibility problem (SFP) and the convex feasibility problem (CFP), see [4]. Let $S: H_{1} \rightarrow H_{1}$ and $T: H_{2} \rightarrow H_{2}$ be two mappings satisfying $F(S)=\left\{x \in H_{1}: S x=x\right\} \neq \phi$ and $F(T)=\left\{x \in H_{2}\right.$ : $T x=x\} \neq \phi$, respectively. The split common fixed point problem for mappings $S$ and $T$ is to find a point $q \in H_{1}$ with the property

$$
q \in F(S), \quad A q \in F(T),
$$

where $A$ is a bounded linear operator from $H_{1}$ to $H_{2}$. We use $\Gamma$ to denote the set of solutions of SCFP (1.2).

We first recall some definitions, notations, and conclusions which will be used in proving our main results.

Let $E$ be a Banach space. A mapping $T: E \rightarrow E$ is said to be demiclosed at origin, if for any sequence $\left\{x_{n}\right\} \subset E$ with $x_{n} \rightarrow x^{*}$ and $\left\|(I-T) x_{n}\right\| \rightarrow 0$, then $x^{*}=T x^{*}$.

A Banach space $E$ is said to satisfy Opial's condition, if for any sequence $\left\{x_{n}\right\}$ in $E$, $x_{n} \rightarrow x^{*}$ implies that

$$
\liminf _{n \rightarrow \infty}\left\|x_{n}-x^{*}\right\|<\liminf _{n \rightarrow \infty}\left\|x_{n}-y\right\|, \quad \forall y \in E \text { with } y \neq x^{*}
$$

It is well known that every Hilbert space satisfies Opial's condition.

Definition 1.1. Let $H$ be a real Hilbert space, $T$ a mapping from $H$ into itself, and the fixed point set $F(T)$ of $T$ nonempty.

(1) $T$ is said to be quasi-nonexpansive if for all $(x, q) \in H \times F(T)$

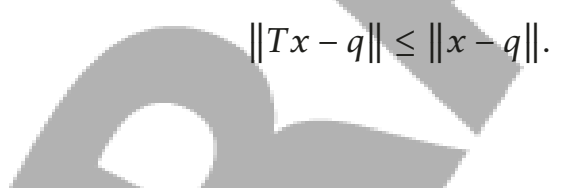

(2) $T$ is said to be quasi-asymptotically nonexpansive if there exists a sequence $\left\{k_{n}\right\} \subset$ $[1, \infty)$ with $k_{n} \rightarrow 1$ as $n \rightarrow \infty$ such that for all $(x, q) \in H \times F(T)$

$$
\left\|T^{n} x-q\right\| \leq k_{n}\|x-q\|, \quad \forall n \geq 1
$$

(3) $T$ is said to be $\left(\left\{\mu_{n}\right\},\left\{\xi_{n}\right\}, \phi\right)$-quasi-total asymptotically nonexpansive if for all $(x, q) \in$ $H \times F(T)$

$$
\left\|T^{n} x-q\right\|^{2} \leq\|x-q\|^{2}+\mu_{n} \phi(\|x-q\|)+\xi_{n}, \quad \forall n \geq 1,
$$

where $\phi:[0, \infty) \rightarrow[0, \infty)$ is a continuous and strictly increasing function with $\phi(0)=0$ and $\left\{\mu_{n}\right\}$ and $\left\{\xi_{n}\right\}$ are two nonnegative real sequences satisfying $\mu_{n} \rightarrow 0$ and $\xi_{n} \rightarrow 0$ as $n \rightarrow \infty$. The class of mappings was introduced by Alber et al. [17] in 2006. 
Abstract and Applied Analysis

(4) $T$ is said to be uniformly L-Lipschitzian if there exists a constant $L>0$ such that for all $(x, y) \in H \times H$

$$
\left\|T^{n} x-T^{n} y\right\| \leq L\|x-y\| .
$$

(5) $T$ is said to be semicompact if for any bounded sequence $\left\{x_{n}\right\} \subset H$ with $\lim _{n \rightarrow \infty} \| x_{n}-$ $T x_{n} \|=0$, there exists a subsequence $\left\{x_{n_{i}}\right\}$ of $\left\{x_{n}\right\}$ such that $\left\{x_{n_{i}}\right\}$ converges strongly to a point $x^{*} \in H$.

Remark 1.2. From Definition 1.1 we can see that a quasi-nonexpansive mapping or an asymptotically quasi-nonexpansive mapping is a $\left(\left\{\mu_{n}\right\},\left\{\xi_{n}\right\}, \phi\right)$-quasi-total asymptotically nonexpansive mapping. But the converse does not hold.

In [9], Moudafi proposed the following iterative algorithm for solving split common fixed problem of quasi-nonexpansive mappings: for arbitrarily chosen $x_{1} \in H_{1}$,

$$
\begin{aligned}
& \left\{u_{n}=x_{n}+\gamma \beta A^{*}(T-I) A x_{n},\right. \\
& x_{n+1}=\left(1-\alpha_{n}\right) u_{n}+\alpha_{n} U u_{n}, \quad n \in N
\end{aligned}
$$

and proved that $\left\{x_{n}\right\}$ converges weakly to a split common fixed point $x^{*} \in \Gamma$, where $U$ : $H_{1} \rightarrow H_{1}$ and $T: H_{2} \rightarrow H_{2}$ are two quasi-nonexpansive mappings and $A: H_{1} \rightarrow H_{2}$ is a bounded linear operator.

Inspired by the work of Moudafi [9, 10], very recently, Qin et al. [12] introduced the following iterative algorithm to study multiples-sets feasibility problem of a finite family of asymptotically quasi-nonexpansive mappings. For arbitrarily chosen $x_{1} \in H_{1},\left\{x_{n}\right\}$ is defined as follows:

$$
\begin{gathered}
y_{n}=x_{n}+\gamma \beta A^{*}\left(T_{n}^{n}-I\right) A x_{n}, \\
x_{n+1}=\left(1-\alpha_{n}\right) y_{n}+\alpha_{n} S_{n}^{n} y_{n}, \quad n \geq 1,
\end{gathered}
$$

where $S_{n}^{n}=S_{n(\bmod N)^{\prime}}^{n} T_{n}^{n}=T_{n(\bmod N)^{\prime}}^{n} n \geq 1, A: H_{1} \rightarrow H_{2}$ is a bounded linear operator. They also proved that $\left\{x_{n}\right\}$ converges strongly or weakly to a multiple-sets split common fixed point of a finite family of asymptotically quasi-nonexpansive mappings in Hilbert spaces under some suitable conditions.

Motivated and inspired by the work of Moudafi $[9,10]$ and Qin et al. [12], in this paper, we study the SCFP $(1.2)$ of $\left(\left\{\mu_{n}\right\},\left\{\xi_{n}\right\}, \phi\right)$-quasi-total asymptotically nonexpansive mappings in Hilbert spaces and obtain some of the strong and weak convergence of the presented algorithm to some $q \in \Gamma$. The results obtained in this paper improve and extend the result of Qin et al. [12], Xu [14], and Yang [16] and others.

By using the well-known equality $\langle x, y\rangle=(1 / 2)\|x\|^{2}+(1 / 2)\|y\|^{2}-(1 / 2)\|x-y\|^{2}$ in Hilbert spaces, we can easily show the following proposition. The proof is omitted.

Proposition 1.3. Let $T: H \rightarrow H$ be a $\left(\left\{\mu_{n}\right\},\left\{\xi_{n}\right\}, \phi\right)$-quasi-total asymptotically nonexpansive mapping. Then for each $q \in F(T)$ and $x \in H$, the following inequalities hold:

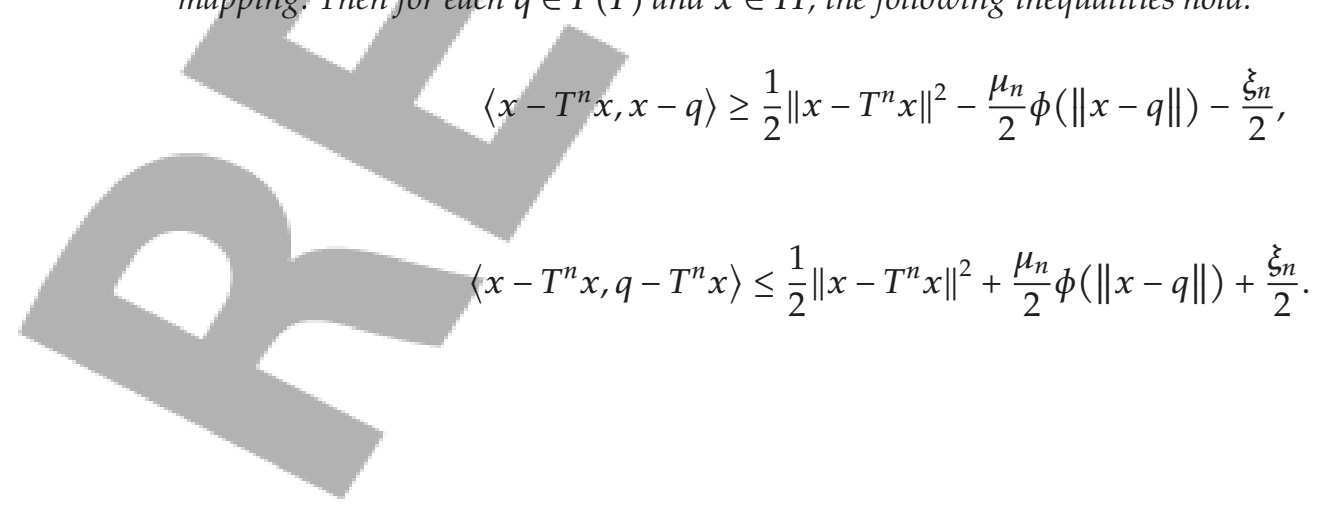


Lemma 1.4. Let $\left\{a_{n}\right\},\left\{b_{n}\right\}$, and $\left\{\delta_{n}\right\}$ be sequences of nonnegative real numbers satisfying

$$
a_{n+1} \leq\left(1+\delta_{n}\right) a_{n}+b_{n} .
$$

If $\sum_{n=1}^{\infty} \delta_{n}<\infty$ and $\sum_{n=1}^{\infty} b_{n}<\infty$, then the $\lim _{n \rightarrow \infty} a_{n}$ exists.

\section{Main Results}

For solving split common fixed point problem (1.2), we assume that the following conditions are satisfied:

(i) $H_{1}$ and $H_{2}$ are two real Hilbert spaces, and $A: H_{1} \rightarrow H_{2}$ is a bounded linear operator;

(ii) $S: H_{1} \rightarrow H_{1}$ is uniformly $L_{1}$-Lipschitzian and $\left(\left\{\mu_{n}^{(1)}\right\},\left\{\xi_{n}^{(1)}\right\}, \phi_{1}\right)$-quasi-total asymptotically nonexpansive mapping and $T: H_{2} \rightarrow H_{2}$ is uniformly $L_{2}$ Lipschitzian and $\left(\left\{\mu_{n}^{(2)}\right\},\left\{\xi_{n}^{(2)}\right\}, \phi_{2}\right)$-quasi-total asymptotically nonexpansive mapping satisfying the following conditions:

(a) $C:=F(S) \neq \emptyset, Q:=F(T) \neq \emptyset$;

(b) $\mu_{n}=\max \left\{\mu_{n}^{(1)}, \mu_{n}^{(2)}\right\}, \xi_{n}=\max \left\{\xi_{n}^{(1)}, \xi_{n}^{(2)}\right\}, n \geq 1$, and $\sum_{n=1}^{\infty} \mu_{n}<\infty$, $\sum_{n=1}^{\infty} \xi_{n}<\infty$;

(c) $\phi=\max \left\{\phi_{1}, \phi_{2}\right\}$ and there exists two positive constant $M$ and $M^{*}$ such that $\phi(\lambda) \leq M^{*} \lambda^{2}$ for all $\lambda \geq M$.

Theorem 2.1. Let $H_{1}, H_{2}, A, S, T, C, Q, L_{1}, L_{2},\left\{\mu_{n}\right\},\left\{\xi_{n}\right\}$, and $\phi$ be the same as above. Let $\left\{x_{n}\right\}$ be the sequence generated by: arbitrarily chosen $x_{1} \in H_{1}$

$$
\begin{gathered}
u_{n}=x_{n}+\gamma A^{*}\left(T^{n}-I\right) A x_{n}, \\
x_{n+1}=\left(1-\alpha_{n}\right) u_{n}+\alpha_{n} S^{n} u_{n}, \quad n \geq 1,
\end{gathered}
$$

where $\left\{\alpha_{n}\right\}$ is a sequence in $[\alpha, 1-\alpha]$ for some $\alpha \in(0,1)$ and $\gamma>0$ is a constant satisfying the following condition:

$$
\text { (d) } r \in\left(0,1 /\|A\|^{2}\right) \text {. }
$$

If $T$ and $S$ both are demi-closed at origin and $\Gamma \neq \emptyset$, then

(I) the sequence $\left\{x_{n}\right\}$ converges weakly to a split common fixed point $x^{*} \in \Gamma$;

(II) in addition, if $S$ is also semicompact, then $\left\{x_{n}\right\}$ and $\left\{u_{n}\right\}$ both converge strongly to $a x^{*} \in \Gamma$.

Proof. (I) The proof will be divided into 4 steps.

Step 1. We prove that $\lim _{n \rightarrow \infty}\left\|x_{n}-q\right\|$ and $\lim _{n \rightarrow \infty}\left\|u_{n}-q\right\|$ exist, and $\lim _{n \rightarrow \infty}\left\|x_{n}-q\right\|=$ $\lim _{n \rightarrow \infty}\left\|u_{n}-q\right\|$ for each $q \in \Gamma$. Since $\phi$ is a continuous and increasing function, as $\lambda \geq 0$, we can obtain that

$$
\phi(\lambda) \leq \phi(M)+M^{*} \lambda^{2}
$$


Abstract and Applied Analysis

Taking $q \in \Gamma$, that is $q \in F(S)=C$ and $A q \in F(T)=Q$, and using (1.10), (2.1), and (2.2), we have

$$
\begin{aligned}
\left\|x_{n+1}-q\right\|^{2} \leq & \left\|u_{n}-q-\alpha_{n}\left(u_{n}-S^{n} u_{n}\right)\right\|^{2} \\
= & \left\|u_{n}-q\right\|^{2}-2 \alpha_{n}\left\langle u_{n}-q, u_{n}-S^{n} u_{n}\right\rangle+\alpha_{n}^{2}\left\|u_{n}-S^{n} u_{n}\right\|^{2} \\
\leq & \left\|u_{n}-q\right\|^{2}-\alpha_{n}\left(1-\alpha_{n}\right)\left\|u_{n}-S^{n} u_{n}\right\|^{2} \\
& +\alpha_{n} \mu_{n}\left(\phi(M)+M^{*}\left(\left\|u_{n}-q\right\|\right)^{2}\right)+\alpha_{n} \xi_{n} \\
= & \left(1+\alpha_{n} \mu_{n} M^{*}\right)\left\|u_{n}-q\right\|^{2}-\alpha_{n}\left(1-\alpha_{n}\right)\left\|u_{n}-S^{n} u_{n}\right\|^{2} \\
& +\alpha_{n} \mu_{n} \phi(M)+\alpha_{n} \xi_{n}, \\
\left\|u_{n}-q\right\|^{2}= & \left\|x_{n}+\gamma A^{*}\left(T^{n}-I\right) A x_{n}-q\right\|^{2} \\
= & \left\|x_{n}-q\right\|^{2}+\gamma^{2}\left\|A^{*}\left(T^{n}-I\right) A x_{n}\right\|^{2}+2 \gamma\left\langle x_{n}-q, A^{*}\left(T^{n}-I\right) A x_{n}\right\rangle \\
= & \left\|x_{n}-q\right\|^{2}+\gamma^{2}\left\langle\left(T^{n}-I\right) A x_{n}, A A^{*}\left(T^{n}-I\right) A x_{n}\right\rangle \\
& +2 \gamma\left\langle x_{n}-q, A^{*}\left(T^{n}-I\right) A x_{n}\right\rangle,
\end{aligned}
$$

where

$$
\begin{aligned}
\gamma^{2}\left\langle\left(T^{n}-I\right) A x_{n}, A A^{*}\left(T^{n}-I\right) A x_{n}\right\rangle & \leq\|A\|^{2} \gamma^{2}\left\langle\left(T^{n}-I\right) A x_{n},\left(T^{n}-I\right) A x_{n}\right\rangle \\
& \leq\|A\|^{2} \gamma^{2}\left\|\left(T^{n}-I\right) A x_{n}\right\|^{2}, \\
2 \gamma\left\langle x_{n}-q, A^{*}\left(T^{n}-I\right) A x_{n}\right\rangle & =2 \gamma\left\langle A\left(x_{n}-q\right),\left(T^{n}-I\right) A x_{n}\right\rangle \\
& =2 \gamma\left\langle A\left(x_{n}-q\right)+\left(T^{n}-I\right) A x_{n}-\left(T^{n}-I\right) A x_{n},\left(T^{n}-I\right) A x_{n}\right\rangle \\
& =2 \gamma\left\langle A\left(x_{n}-q\right)+\left(T^{n}-I\right) A x_{n}-\left(T^{n}-I\right) A x_{n},\left(T^{n}-I\right) A x_{n}\right\rangle \\
& =2 \gamma\left(\left\langle T^{n}\left(A x_{n}\right)-A q,\left(T^{n}-I\right) A x_{n}\right\rangle-\left\|\left(T^{n}-I\right) A x_{n}\right\|^{2}\right) .
\end{aligned}
$$

Using (1.11), we have

$$
\begin{aligned}
& 2 \gamma\left(\left\langle T^{n}\left(A x_{n}\right)-A q,\left(T^{n}-I\right) A x_{n}\right\rangle-\left\|\left(T^{n}-I\right) A x_{n}\right\|^{2}\right) \\
& \leq \gamma\left\|\left(T^{n}-I\right) A x_{n}\right\|^{2}+\gamma \mu_{n} \phi\left(\left\|A x_{n}-A q\right\|\right)+\gamma \xi_{n}-2 \gamma\left\|\left(T^{n}-I\right) A x_{n}\right\|^{2} \\
& \quad \leq-\gamma\left\|\left(T^{n}-I\right) A x_{n}\right\|^{2}+\gamma \mu_{n} M^{*}\|A\|^{2}\left\|x_{n}-q\right\|+\gamma \mu_{n} \phi(M)+\gamma \xi_{n} .
\end{aligned}
$$


Substituting (2.5) and (2.7) into (2.4) and simplifying, we obtain

$$
\begin{aligned}
\left\|u_{n}-q\right\|^{2} \leq & \left\|x_{n}-q\right\|^{2}+\gamma^{2}\|A\|^{2}\left\|\left(T^{n}-I\right) A x_{n}\right\|^{2}-\gamma\left\|\left(T^{n}-I\right) A x_{n}\right\|^{2} \\
& +\gamma \mu_{n} M^{*}\|A\|^{2}\left\|x_{n}-q\right\|^{2}+\gamma \mu_{n} \phi(M)+\gamma \xi_{n} \\
\leq & \left(1+\gamma \mu_{n} M^{*}\|A\|^{2}\right)\left\|x_{n}-q\right\|^{2}-\gamma\left(1-\gamma\|A\|^{2}\right)\left\|\left(T^{n}-I\right) A x_{n}\right\|^{2} \\
& +\gamma \mu_{n} \phi(M)+\gamma \xi_{n} .
\end{aligned}
$$

Substituting (2.8) into (2.3) and simplifying, we have

$$
\begin{aligned}
\left\|x_{n+1}-q\right\|^{2} \leq & \left(1+\alpha_{n} \mu_{n} M^{*}\right)\left\{\left(1+\gamma \mu_{n} M^{*}\|A\|^{2}\right)\left\|x_{n}-q\right\|^{2}\right. \\
& \left.-\gamma\left(1-\gamma\|A\|^{2}\right)\left\|\left(T^{n}-I\right) A x_{n}\right\|^{2}+\gamma \mu_{n} \phi(M)+\gamma \xi_{n}\right\} \\
& -\alpha_{n}\left(1-\alpha_{n}\right)\left\|u_{n}-S^{n} u_{n}\right\|^{2}+\alpha_{n} \mu_{n} \phi(M)+\alpha_{n} \xi_{n} \\
= & \left(1+b_{n}\right)\left\|x_{n}-q\right\|^{2}-\left(1+\alpha_{n} \mu_{n} M^{*}\right) \gamma\left(1-\gamma\|A\|^{2}\right)\left\|\left(T^{n}-I\right) A x_{n}\right\|^{2} \\
& -\alpha_{n}\left(1-\alpha_{n}\right)\left\|u_{n}-S^{n} u_{n}\right\|^{2}+c_{n},
\end{aligned}
$$

where

$$
\begin{gathered}
b_{n}=\alpha_{n} \mu_{n} M^{*}+\gamma \mu_{n} M^{*}\|A\|^{2}+\gamma\|A\|^{2} \alpha_{n} \mu_{n}^{2}\left(M^{*}\right)^{2}, \\
c_{n}=\left(1+\alpha_{n} \mu_{n} M^{*}\right)\left(\gamma \mu_{n} \phi(M)+\alpha_{n} \xi_{n}\right)+\alpha_{n} \mu_{n} \phi(M)+\alpha_{n} \xi_{n} .
\end{gathered}
$$

Since $\sum_{n=1}^{\infty} \mu_{n}<\infty$ and $\sum_{n=1}^{\infty} \xi_{n}<\infty$, so $\sum_{n=1}^{\infty} b_{n}<\infty$ and $\sum_{n=1}^{\infty} c_{n}<\infty$. By Condition (4), we have

$$
\left\|x_{n+1}-q\right\|^{2} \leq\left(1+b_{n}\right)\left\|x_{n}-q\right\|^{2}+c_{n}
$$

Therefore, it follows from Lemma 1.4 that $\lim _{n \rightarrow \infty}\left\|x_{n}-q\right\|$ exists.We now prove that $\lim _{n \rightarrow \infty}\left\|u_{n}-q\right\|$ exists for each $q \in \Gamma$. Since $\lim _{n \rightarrow \infty}\left\|x_{n}-q\right\|$ exists, from (2.9), we have

$$
\begin{gathered}
\left(1+\alpha_{n} \mu_{n} M^{*}\right) \gamma\left(1-\gamma\|A\|^{2}\right)\left\|\left(T^{n}-I\right) A x_{n}\right\|^{2}+\alpha_{n}\left(1-\alpha_{n}\right)\left\|u_{n}-S^{n} u_{n}\right\|^{2} \\
\leq\left\|x_{n}-q\right\|^{2}-\left\|x_{n+1}-q\right\|^{2}-b_{n}\left\|x_{n}-q\right\|^{2} \longrightarrow 0, \quad \text { as } n \longrightarrow \infty
\end{gathered}
$$

This together with Condition (4) implies that

$$
\begin{gathered}
\lim _{n \rightarrow \infty}\left\|u-S^{n} u_{n}\right\|=0, \\
\lim _{n \rightarrow \infty}\left\|\left(T^{n}-I\right) A x_{n}\right\|=0 .
\end{gathered}
$$


Abstract and Applied Analysis

Thus, since $\lim _{n \rightarrow \infty}\left\|x_{n}-q\right\|$ exists, it follows from (2.4) and (2.14) that $\lim _{n \rightarrow \infty}\left\|u_{n}-q\right\|$ exists and $\lim _{n \rightarrow \infty}\left\|x_{n}-q\right\|=\lim _{n \rightarrow \infty}\left\|u_{n}-q\right\|$.

Step 2. Now we prove that $\lim _{n \rightarrow \infty}\left\|x_{n+1}-x_{n}\right\|=0$ and $\lim _{n \rightarrow \infty}\left\|u_{n+1}-u_{n}\right\|=0$.

As a matter of fact, it follows from (2.1) that

$$
\begin{aligned}
\left\|x_{n+1}-x_{n}\right\| & =\left\|\left(1-\alpha_{n}\right) u_{n}+\alpha_{n} S^{n} u_{n}-x_{n}\right\| \\
& =\left\|\left(1-\alpha_{n}\right)\left(x_{n}+\gamma A^{*}\left(T^{n}-I\right) A x_{n}\right)+\alpha_{n} S^{n} u_{n}-x_{n}\right\| \\
& =\left\|\left(1-\alpha_{n}\right) \gamma A^{*}\left(T^{n}-I\right) A x_{n}+\alpha_{n}\left(S^{n} u_{n}-x_{n}\right)\right\| \\
& =\left\|\left(1-\alpha_{n}\right) \gamma A^{*}\left(T^{n}-I\right) A x_{n}+\alpha_{n}\left(S^{n} u_{n}-u_{n}\right)+\alpha_{n}\left(u_{n}-x_{n}\right)\right\| \\
& =\left\|\left(1-\alpha_{n}\right) \gamma A^{*}\left(T^{n}-I\right) A x_{n}+\alpha_{n}\left(S^{n} u_{n}-u_{n}\right)+\alpha_{n} \gamma A^{*}\left(T^{n}-I\right) A x_{n}\right\| \\
& =\left\|\gamma A^{*}\left(T^{n}-I\right) A x_{n}+\alpha_{n}\left(S^{n} u_{n}-u_{n}\right)\right\| .
\end{aligned}
$$

In view of (2.13) and (2.14) we have that

$$
\lim _{n \rightarrow \infty}\left\|x_{n+1}-x_{n}\right\|=0 .
$$

Similarly, it follows from (2.1), (2.14), and (2.16) that

$$
\begin{aligned}
\left\|u_{n+1}-u_{n}\right\|= & \left\|x_{n+1}+\gamma A^{*}\left(T^{n+1}-I\right) A x_{n+1}-\left(x_{n}+\gamma A^{*}\left(T^{n}-I\right) A x_{n}\right)\right\| \\
\leq & \left\|x_{n+1}-x_{n}\right\|+\gamma\left\|A^{*}\left(T^{n+1}-I\right) A x_{n+1}\right\| \\
& +\gamma\left\|A^{*}\left(T^{n}-I\right) A x_{n}\right\| \longrightarrow 0, \quad(n \longrightarrow \infty) .
\end{aligned}
$$

Step 3. Next, we prove that $\left\|u_{n}-S u_{n}\right\| \rightarrow 0$ and $\left\|A x_{n}-T A x_{n}\right\| \rightarrow 0$ as $n \rightarrow \infty$.

Setting $\eta_{n}:=\left\|u_{n}-S^{n} u_{n}\right\|$, since $S$ is uniformly L-Lipschitzian continuous, it follows from (2.13), (2.16), and (2.17) that

Similarly, we have

$$
\left\|A x_{n}-T A x_{n}\right\| \longrightarrow 0, \quad(n \longrightarrow \infty)
$$


Step 4. Finally, we prove that $x_{n} \rightarrow x^{*}$ and $u_{n} \rightarrow x^{*}$, where $x^{*} \in \Gamma$. Since $\left\{u_{n}\right\}$ is bounded, there exists a subsequence $\left\{u_{n_{i}}\right\}$ of $\left\{u_{n}\right\}$ such that $u_{n_{i}} \rightarrow x^{*}$ (some point in $H_{1}$ ). From (2.18) we have $\lim _{i \rightarrow \infty}\left\|u_{n_{i}}-S u_{n_{i}}\right\|=0$. Since $S$ is demi-closed at zero, we know that $x^{*} \in F(S)$. Moreover, it follows from (2.1) and (2.14) that

$$
x_{n_{i}}=u_{n_{i}}-\gamma A^{*}\left(T^{n_{i}}-I\right) A x_{n_{i}} \rightarrow x^{*} .
$$

Since $A$ is a linear bounded operator, it gets $A x_{n_{i}} \rightarrow A x^{*}$. In view of (2.19) we have $\lim _{i \rightarrow \infty}\left\|A x_{n_{i}}-T A x_{n_{i}}\right\|=0$.

Again since $T$ is demi-closed at zero, we know that $A x^{*} \in F(T)$. This implies that $x^{*} \in \Gamma$.

Assume that there exists another subsequence $\left\{u_{n_{k}}\right\}$ of $\left\{u_{n}\right\}$ such that $\left\{u_{n_{k}}\right\}$ converges weakly to a point $y^{*} \in H$ with $y^{*} \neq x^{*}$. Using the same argument above, we know that $y^{*} \in \Gamma$. Since each Hilbert space possesses Opial's property, we have

$$
\begin{aligned}
\liminf _{i \rightarrow \infty}\left\|u_{n_{i}}-x^{*}\right\| & <\liminf _{i \rightarrow \infty}\left\|u_{n_{i}}-y^{*}\right\|=\lim _{n \rightarrow \infty}\left\|u_{n}-y^{*}\right\| \\
& =\liminf _{k \rightarrow \infty}\left\|u_{n_{k}}-y^{*}\right\|<\liminf _{k \rightarrow \infty}\left\|u_{n_{k}}-x^{*}\right\| \\
& =\lim _{n \rightarrow \infty}\left\|u_{n}-x^{*}\right\|=\liminf _{i \rightarrow \infty}\left\|u_{n_{i}}-x^{*}\right\|,
\end{aligned}
$$

which is a contradiction. This implies that $\left\{u_{n}\right\}$ converges weakly to the point $x^{*} \in \Gamma$. Since $x_{n}=u_{n}-\gamma A^{*}\left(T^{n}-I\right) A x_{n}$, we know that $\left\{x_{n}\right\}$ converges weakly to $x^{*} \in \Gamma$. The proof of conclusion(I) is completed.

Proof of Conclusion (II). Since $S$ is semi-compact, it follows from Step 4 that there exists a subsequence of $\left\{u_{n_{i}}\right\}$ (without loss of generality, we still denote it by $\left.\left\{u_{n_{i}}\right\}\right)$ such that $\left\{u_{n_{i}}\right\} \rightarrow$ $u^{*} \in H$ (some point in $H$ ). Since $\left\{u_{n_{i}}\right\} \rightarrow \mathrm{x}^{*}$, this implies that $x^{*}=u^{*}$. And so $\left\{u_{n_{i}}\right\} \rightarrow x^{*} \in \Gamma$ as $i \rightarrow \infty$. Since $\lim _{n \rightarrow \infty}\left\|x_{n}-q\right\|$ and $\lim _{n \rightarrow \infty}\left\|u_{n}-q\right\|$ exist, and $\lim _{n \rightarrow \infty}\left\|x_{n}-q\right\|=$ $\lim _{n \rightarrow \infty}\left\|u_{n}-q\right\|$ for each $q \in \Gamma$, we know that $\lim _{n \rightarrow \infty}\left\|u_{n}-x^{*}\right\|=\lim _{n \rightarrow \infty}\left\|x_{n}-x^{*}\right\|=0$. This implies that $\left\{x_{n}\right\}$ and $\left\{u_{n}\right\}$ both converge strongly to a $x^{*} \in \Gamma$. The proof is completed.

\section{Acknowldgments}

The authors would like to express their thanks to the referees for helpful suggestions and comments. This work was supported by the Natural Science Foundation of Yunnan Province (Grant no. 2011FB074), P.R. China.

\section{References}

[1] Y. Censor and T. Elfving, "A multiprojection algorithm using Bregman projections in a product space," Numerical Algorithms, vol. 8, no. 2-4, pp. 221-239, 1994.

[2] C. Byrne, "Iterative oblique projection onto convex sets and the split feasibility problem," Inverse Problems, vol. 18, no. 2, pp. 441-453, 2002. 
[3] Y. Censor, T. Elfving, N. Kopf, and T. Bortfeld, "The multiple-sets split feasibility problem and its applications for inverse problems," Inverse Problems, vol. 21, no. 6, pp. 2071-2084, 2005.

[4] Y. Censor and A. Segal, "The split common fixed point problem for directed operators," Journal of Convex Analysis, vol. 16, no. 2, pp. 587-600, 2009.

[5] Y. Censor, T. Bortfeld, B. Martin, and T. Trofimov, "A unified approach for inversion problem in intensity-modolated radiation therapy," Physics in Medicine and Biology, vol. 51, pp. 2353-2365, 2006.

[6] Y. Censor, A. Motova, and A. Segal, "Perturbed projections and subgradient projections for the multiple-sets split feasibility problem," Journal of Mathematical Analysis and Applications, vol. 327, no. 2, pp. 1244-1256, 2007.

[7] G. Lopez, V. Martin, H. K. Xu et al., "Iterative algorithms for the muitiple-sets split feasibility problem," in Biomedical Mathematics: Promising Directions in Imaging, Therapy Planning and inverse Problems, Y. Censor, M. Jiang, and G. Wang, Eds., pp. 243-279, Medical Physics, Madison, Wis, USA, 2009.

[8] Y. Dang and Y. Gao, "The strong convergence of a KM-CQ-like algorithm for a split feasibility problem," Inverse Problems, vol. 27, no. 1, Article ID 015007, 9 pages, 2011.

[9] A. Moudafi, "A note on the split common fixed-point problem for quasi-nonexpansive operators," Nonlinear Analysis, vol. 74, no. 12, pp. 4083-4087, 2011.

[10] A. Moudafi, "The split common fixed-point problem for demicontractive mappings," Inverse Problems, vol. 26, no. 5, Article ID 055007, 6 pages, 2010.

[11] S. Maruster and C. Popirlan, "On the Mann-type iteration and the convex feasibility problem," Journal of Computational and Applied Mathematics, vol. 212, no. 2, pp. 390-396, 2008.

[12] L. J. Qin, L. Wang, and S. S. Chang, "Multiple-set split feasibility problem for a finite family of asymptotically quasi-nonexpansive mappings," PanAmerican Mathematical Journal, vol. 22, no. 1, pp. 37-45, 2012.

[13] F. Wang and H. K. Xu, "Approximating curve and strong convergence of the CQ algorithm for the split feasibility problem," Journal of Inequalities and Applications, vol. 2010, Article ID 102085, 13 pages, 2010.

[14] H. K. Xu, "Iterative methods for the split feasibility problem in infinite-dimensional Hilbert spaces," Inverse Problems, vol. 26, no. 10, Article ID 105018, 17 pages, 2010.

[15] H. K. Xu, "A variable Krasnosel'skii-Mann algorithm and the multiple-set split feasibility problem," Inverse Problems, vol. 22, no. 6, pp. 2021-2034, 2006.

[16] Q. Yang, "The relaxed CQ algorithm solving the split feasibility problem," Inverse Problems, vol. 20, no. 4, pp. 1261-1266, 2004.

[17] Y. I. Alber, C. E. Chidume, and H. Zegeye, "Approximating fixed points of total asymptotically nonexpansive mappings," Fixed Point Theory and Applications, vol. 2006, Article ID 10673, 20 pages, 2006.

[18] H. K. Xu, "Iterative algorithms for nonlinear operators," Journal of the London Mathematical Society, vol. 66 , no. 1, pp. 240-256, 2002.

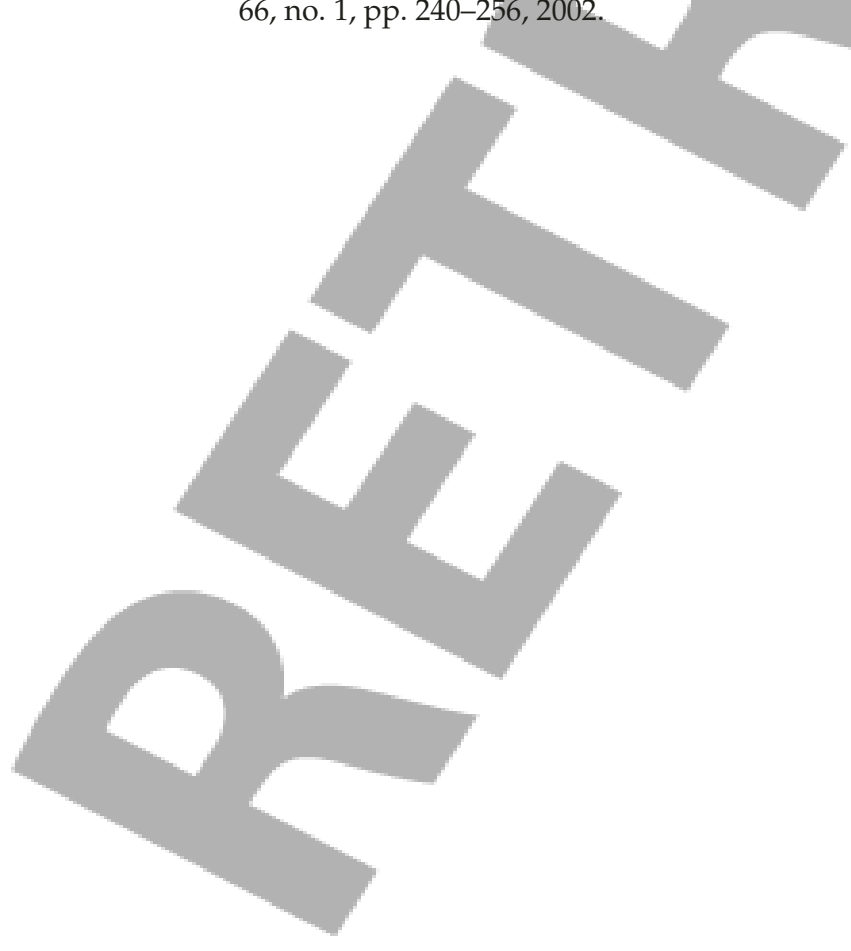

